\title{
Assessment of Heart Rate Variability in Adolescents with Different Levels of Personal Anxiety in Physical and Mental Tests
}

\author{
Natalia V. Efimova, Inna V. Myl'nikova \\ East-Siberian Institute of Medical and Ecological Research, Angarsk, Russian \\ Email: medecolab@inbox.ru
}

How to cite this paper: Efimova, N. V., \& Myl'nikova, I. V. (2018). Assessment of Heart Rate Variability in Adolescents with Different Levels of Personal Anxiety in Physical and Mental Tests. Psychology, 9, 2709-2717.

https://doi.org/10.4236/psych.2018.913155

Received: September 20, 2018

Accepted: December 3, 2018

Published: December 6, 2018

Copyright $\odot 2018$ by authors and Scientific Research Publishing Inc. This work is licensed under the Creative Commons Attribution International License (CC BY 4.0).

http://creativecommons.org/licenses/by/4.0/

\begin{abstract}
The purpose of this research was to investigate the relationship of the personal anxiety level and the markers of autonomic nervous system function in schoolchildren. Methods: A total of 124 adolescents were examined using the questionnaire "The scale of reactive and personal anxiety" (PA) and an analysis of heart rate variability (HRV). The data were analysed and used to classify personal anxiety into 3 groups: low PA ( $<30$ points), moderate PA $(30 \leq \mathrm{PA}<$ 45 points), and high PA ( $>30$ points). Associations between personal anxiety and HRV markers were assessed using Spearman's rank correlation and the odds ratio (OR). Results: The optimal type of heart rhythm regulation was noted among $81.8 \%$ of adolescents with low PA compared to $56.8 \%$ of schoolchildren with moderate PA and $63.8 \%$ with high PA. Emotional stress was also significantly higher for the adolescents with a low level of PA vs. a moderate level of PA in both tests: in the orthostatic test ("high level" $R_{I} O R$ $=1.87, p=0.001$ ) and in the "through the mind" test ("high level" $\mathrm{RR}_{\mathrm{I}} \mathrm{OR}=$ 1.87, $p<0.001$; "low level" $\mathrm{OR}=1.88, p<0.001$ ). Conclusion: Emotional stress causes the most significant shifts of the functional indicators of the autonomic nervous and cardiovascular systems in schoolchildren, especially in those with high levels of personal anxiety, as determined by an orthostatic test.
\end{abstract}

\section{Keywords}

Adolescents, Personal Anxiety, Heart Rate Variability, Orthostatic Test, "Through the Mind" Test

\section{Introduction}

One widely used measure of autonomic nervous system (ANS) activity is the 
beat-to-beat variations in cardiac rhythm as indexed by heart rate variability, which is currently one of the most widespread methods for the quick assessment of the functional state of different autonomic regulation elements and hence the whole body (Fagundes et al., 2011, Jarczok et al., 2013, Voltas et al., 2016). HRV has been independently associated with morbidity and mortality, especially in relation to cardiovascular disease (Jarczok et al., 2013, Thayer et al. 2010), fatigue (Fagundes et al., 2011), work stress (Loerbroks et al., 2010), and psychological status (Fagan et al., 2017, Dzhebrailova \& Suleymanova, 2012, Koenig et al., 2018). Psychological stress is thought to be a dominant factor in the lives of many people. Adolescents are also exposed to psychological stress, depression and anxiety. This exposure suggests the necessity to introduce dynamic control of the functional state of adolescents.

However, the use of the formal analysis of HRV, which does not take into account individual features of autonomic regulation and psychological characteristics, sometimes leads to a distortion of the results. This is an important aspect of the system approach to considering the very complicated mechanism of the regulation of physiological functions, whose activity can be assessed by complex analysis data. This research aimed to investigate the relationship between personal anxiety level and markers of the autonomic nervous system function in adolescents.

\section{Methods}

The research was carried out in three stages. The study was conducted in accordance with the Declaration of Helsinki of protection of the rights of patients, (p.21-28. v.64th WMA General Assembly, 2013) and was approved by the local ethics committee (East-Siberian Institute of Medical and Ecological Research). All parents of participants gave written informed consent prior to examination. At the first stage, a voluntary comprehensive medical examination was carried out, including a survey and a general medical examination of 650 schoolchildren from 4 schools in the southern part of the Irkutsk region (Russia), of which 124 adolescents were invited for further examination (mean age 13.5 years, $\mathrm{SD}=2.1$, $53.2 \%$ female). The exclusion criteria were: suffering from a endocrine, neurological, developmental, psychiatric disorder; or cardiovascular or respiratory disease, as per medical records that were reported by parents. As we examined HRV in a sample of healthy adolescents, students with any defect of cardiograms were excluded $(N=16)$. A total of 748 investigations were performed. Participants were in self-reported good health and had no history of cardiovascular system disease. The participants had not had additional physical exercise for 6 months. The adolescents were interviewed using the questionnaire The scale of reactive and personal anxiety" by C.D. Spielberger (adapted into Russian by Yu. L. Hanin) (Hanin \& Spielberger, 1981). It clearly differentiates between the temporary condition of "personal anxiety" and the more general and long-standing quality of "trait anxiety". The questionnaire has forty questions with a range of 
four possible responses to each. Evaluation of the test results will be carried out on a scale: up to 30 points-low, 31 - 44 points-moderate level, more than 45 points-high level of anxiety. The condition of the autonomic nervous system (ANS) was recorded using the automated program "VNS-Micro" (Neurosoft Company, Ivanovo) in the initial state and during performance of functional tests, including the orthostatic test and the "through the mind"test (calculated test). Raw beat-to-beat intervals $\left(\mathrm{RR}_{\mathrm{I}}\right)$ were analysed by researchers as previously described (Task Force ..., 1996).

The results of the following were categorized into quartiles (Q1 - Q3): the mean $\mathrm{RR}_{\mathrm{I}}$; $\mathrm{Mo}$ (mode of $\mathrm{RR}_{\mathrm{I}}$ ); $\mathrm{AMo}$ (amplitude of Mo); $\mathrm{MxDMn}$ (variable range, difference between the maximal and minimal value); SDNN (мс; standard deviation of normal RR intervals); RMSSD (MC, root mean square of successive differences of RR interval); index of tension of regulatory systems or stress index (by R.M. Baevsky; calculated as ITRS $=\mathrm{AMo} / 2 \mathrm{Mo} \times \mathrm{MxDMn}$ ); the total frequency domain power (TP); and the frequency domain power in the low frequency (LF) $(0.04-0.15 \mathrm{~Hz})$, very low-frequency (VLF) $(<0.04 \mathrm{~Hz})$ and high frequency $(\mathrm{HF})(0.15-0.4 \mathrm{~Hz})$ ranges. Significant differences were assessed by the criterion of Spearman $(p<0.05)$. Differences between the full sample and the analysis sample were determined by t-test for the continuous variables and Yates's corrected $\chi^{2}$ test for the categorical variables.

The second stage included the processing of the received individual data. The quick determination of the type of regulation was based on the studies of N. I. Shlyk and included only one of two temporary and spectral HRV indices, namely, the SI- and VLF-based indices (Shlyk, 2016). The first index SI, characterizes the degree of dominance of the central regulation circuit activity over the autonomic circuit activity, while the second index, VLF reflects the mobilization of energy and metabolic reserves in the case of physical and psychoemotional loads. The proposed classification is based on the central and autonomic circuits controlling physiological functions. We differentiated four prevailing types of regulation: moderate 1) and marked 2) dominance of the central regulation circuit; and moderate 3) and marked 4) dominance of the autonomic regulation circuit. Significant differences were assessed by the Student's t-test $(p<0.05)$.

The personal anxiety (PA) data were analysed and used to classify personal anxiety into 3 groups: low PA ( $<30$ points), moderate PA $(31 \leq \mathrm{PA}<45)$, high PA $(\geq 45)$.

Bivariate associations between PA and continuous biomarkers were assessed using the nonparametric Spearman's rank correlation coefficient $\left(r_{\mathrm{sp}}\right)$. Significant differences were assessed by Yates' corrected $\chi^{2}$ test for the categorical variables. To show the relative strength of association, an odds ratios (OR) of each category for PA and its respective 95\% confidence interval was calculated.

\section{Results}

The results of the analysis of HRV in adolescents are presented in Table $1 . R R_{I}$ 
Table 1. Median and quartile range of indicators of heart rate variability in adolescents at different tests.

\begin{tabular}{cccc}
\hline Indicators & Initial stage & Orthostatic test & “Through the mind" test \\
\hline RR $_{\mathrm{I}}$ & $76(70 ; 86)$ & $99(92 ; 108)$ & $88(80 ; 96)$ \\
SDNN, MC & $48.9(40.1 ; 60.3)$ & $51.5(38.5 ; 62.2)$ & $60.5(47.1 ; 71.7)$ \\
RMSSD, Mc & $40.4(29.7 ; 57.3)$ & $22.5(16.2 ; 29.8)$ & $34.9(25.1 ; 45.9)$ \\
TP, MC & $3721(2516 ; 5328)$ & $4567(2731 ; 6517)$ & $6025(3777 ; 8199)$ \\
VLF, MC ${ }^{2}$ & $1098(769 ; 1858)$ & $1711(1074 ; 2647)$ & $1129(690 ; 1913)$ \\
LF, MC ${ }^{2}$ & $1332(824 ; 2070)$ & $1859(1094 ; 3014)$ & $3152(1915 ; 4517)$ \\
HF, MC ${ }^{2}$ & $896(476 ; 1561)$ & $522(276 ; 1116)$ & $1135(715 ; 1996)$ \\
LF/HF & $1.5(0.9 ; 2.4)$ & $3.3(2.3 ; 4.7)$ & $2.7(1.9 ; 3.8)$ \\
MxDMn, c & $0.3(0.24 ; 0.36)$ & $0.38(0.3 ; 0.54)$ & $0.29(0.25 ; 0.35)$ \\
AMo, \% & $38.4(33.7 ; 47)$ & $42.4(36.5 ; 55.7)$ & $32.1(26.9 ; 39.9)$ \\
ITRS & $83(59 ; 121)$ & $92(58 ; 149)$ & $77(57 ; 121)$ \\
\hline
\end{tabular}

Legend: $\mathrm{RR}_{\mathrm{I}}$, RR intervals; SDNN, standard deviation of normal RR intervals; RMSSD, root mean square of successive differences of RR interval; TP-total frequency power; LF-low frequency $(0.04-0.15 \mathrm{~Hz})$, $\mathrm{VL}-$ very low-frequency $(<0.04 \mathrm{~Hz}) \mathrm{HF}-$ high frequency $(0.15-0.4 \mathrm{~Hz})$; AMo-amplitude of Mo; $\mathrm{MxDMn}-$ variable range; ITRS $=\mathrm{AMo} / 2 \mathrm{Mo} \times \mathrm{MxDMn}-$ index of tension of regulatory systems.

at rest was 77 , increased by 1.3 -fold in the orthostatic test, and by 1.2 -fold in the mental sample. This is due to the activation of the sympathetic influence in the tests. In the orthostatic test, LF increased by 1.4 -fold, with a mental load by 2.4-fold. The spectral composition of the total power of the HRV is different in the tests $\left(\chi^{2}=689.4, p=0.000\right)$.

The PA of the participants ranged from 11 to 74 points, with a mean of 21.35 \pm 3.76. Forty-four schoolchildren demonstrated moderate levels of PA $(35 \% \pm$ 4.28\%), 47 demonstrated high PA (37.9 \pm 4.35$)$, and 33 demonstrated low PA $(26.6 \% \pm 3.96 \%)$ (Table 2).

The prevailing types of vegetative regulation in all examined adolescents were determined by the ratio of the stress index and the spectrum of the very low frequency waves (Table 3). The optimal type of regulation of heart rhythm (III) was noted among $81.8 \%$ of adolescents with low PA compared to $56.8 \%$ of schoolchildren with moderate PA and $63.8 \%$ with high PA. We found that the first type of rhythm regulation in adolescents with low PA was 2.4 times less frequent than in adolescents with moderate PA ( $\chi^{2}$ Yates's corrected $=4.295, p=$ $0.039)$, and 1.9 times higher than in adolescents with high PA $\left(\chi^{2}=0.220, p=\right.$ 0.640). According to N. I. Shlyk, type I reflects a moderate predominance of central regulation of the heart rhythm, a decrease in the activity of the autonomic regulation loop, and a moderate strain of bodily systems. The persons with types II and IV vegetative regulation was absent among of the surveyed adolescents.

Based on the various functional tests, the HRV of the adolescents with high and low PA was higher than that of those with moderate PA (Table 4). In the 
Table 2. Average characteristics of personal anxiety in groups of children.

\begin{tabular}{ccc}
\hline Level personal anxiety & $\begin{array}{c}\text { Average personal anxiety, points } \\
\mathrm{Me} /\left[\mathrm{Q}_{1}-\mathrm{Q}_{3}\right]\end{array}$ & Frequency, per 100 person $(\mathrm{P} \pm \mathrm{SE})^{\mathrm{a}}$ \\
\hline Low & $28 /[27-29]$ & $26.6 \pm 3.96$ \\
Moderate & $39 /[37-41]$ & $35.0 \pm 4.28$ \\
High & $49 /[41-58]$ & $37.9 \pm 4.35$ \\
\hline
\end{tabular}

Legend: ${ }^{a} \mathrm{P} \pm \mathrm{SE}$, percent \pm standard error.

Table 3. Distribution of the surveyed adolescents by types of vegetative regulation (per 100 persons).

\begin{tabular}{ccccccc}
\hline & \multicolumn{5}{c}{ Groups of patients with personal anxiety } \\
Type of regulation & \multicolumn{2}{c}{ Moderate } & \multicolumn{2}{l}{ Low } & \multicolumn{2}{l}{ High } \\
& $\mathrm{n}^{\mathrm{a}}$ & $\mathrm{P} \pm \mathrm{SE}^{\mathrm{b}}$ & $\mathrm{n}$ & $\mathrm{P} \pm \mathrm{SE}$ & $\mathrm{n}$ & $\mathrm{P} \pm \mathrm{SE}$ \\
I & 19 & $43.2 \pm 7.5$ & 6 & $18.2 \pm 6.7$ & 17 & $36.2 \pm 7.0$ \\
III & 25 & $56.8 \pm 7.5$ & 27 & $81.8 \pm 6.7$ & 30 & $63.8 \pm 7.0$ \\
\hline
\end{tabular}

Legend: ${ }^{\mathrm{a}} \mathrm{n}$, number of people surveyed; ${ }^{\mathrm{b}} \mathrm{P} \pm \mathrm{SE}$, percent \pm standard error.

Table 4. HRV markers in adolescents, depending on the level of personal anxiety $\mathrm{Me}\left(\mathrm{Q}_{1}\right.$ $-\mathrm{Q}_{3}$ ).

\begin{tabular}{|c|c|c|c|c|c|}
\hline \multirow{2}{*}{ Indicator } & \multirow{2}{*}{ Test $^{\mathrm{a}}$} & \multicolumn{3}{|c|}{ Groups of patients with personal anxiety } & \multirow{2}{*}{$p=$} \\
\hline & & Moderate (1) & Low (2) & High (3) & \\
\hline \multirow{3}{*}{$\mathrm{TP}, \mathrm{MC}^{2}$} & IS & $3102(1905 ; 4078)$ & $4455(3190 ; 5981)$ & $3903(2449 ; 5428)$ & $\begin{array}{l}P_{1-2}=0.021 \\
P_{1-3}=0.406\end{array}$ \\
\hline & $\mathrm{OT}$ & $3636(2077 ; 5523)$ & $5127(3235 ; 6769)$ & $5203(3022 ; 7299)$ & $\begin{array}{l}P_{1-2}=0.033 \\
P_{1-3}=0.019\end{array}$ \\
\hline & TMT & $5349(3102 ; 8656)$ & $6921(3837 ; 9457)$ & $6287(4509 ; 7655)$ & $\begin{array}{l}P_{1-2}=0.010 \\
P_{1-3}=0.858\end{array}$ \\
\hline \multirow{3}{*}{$\mathrm{VLF}, \mathrm{MC}^{2}$} & IS & $871(735 ; 1628)$ & $1386(801 ; 2058)$ & $1121(817 ; 1677)$ & $\begin{array}{l}P_{1-2}=0.049 \\
P_{1-3}=0.540\end{array}$ \\
\hline & $\mathrm{OT}$ & $1504(882 ; 1969)$ & $2023(1311 ; 2473)$ & $1754(1206 ; 3604)$ & $\begin{array}{l}P_{1-2}=0.047 \\
P_{1-3}=0.599\end{array}$ \\
\hline & TMT & $1104(584 ; 1798)$ & $1189(738 ; 2435)$ & $1101(832 ; 1650)$ & $\begin{array}{l}P_{1-2}=0.767 \\
P_{1-3}=0.301\end{array}$ \\
\hline \multirow{3}{*}{$\mathrm{LF}, \mathrm{MC}^{2}$} & IS & $1174(688 ; 1699)$ & $1752(1121 ; 2150)$ & $1342(749 ; 2142)$ & $\begin{array}{l}P_{1-2}=0.045 \\
P_{1-3}=0.409\end{array}$ \\
\hline & OT & $1492(929 ; 2503)$ & $2123(1370 ; 2996)$ & $1937(1290 ; 3654)$ & $\begin{array}{l}P_{1-2}=0.648 \\
P_{1-3}=0.828\end{array}$ \\
\hline & TMT & $2933(1694 ; 4419)$ & $3101(2285 ; 5201)$ & $3353(2253 ; 4239)$ & $\begin{array}{l}P_{1-2}=0.489 \\
P_{1-3}=0.115\end{array}$ \\
\hline \multirow{3}{*}{$\mathrm{HF}, \mathrm{MC}^{2}$} & IS & $761(458 ; 1079)$ & $1074(720 ; 1900)$ & $920(409 ; 1666)$ & $\begin{array}{l}P_{1-2}=0.012 \\
P_{1-3}=0.039\end{array}$ \\
\hline & OT & $405(219 ; 698)$ & $581(320 ; 1231)$ & $608(371 ; 1301)$ & $\begin{array}{l}P_{1-2}=0.20 \\
P_{1-3}=0.791\end{array}$ \\
\hline & TMT & $884(601 ; 2199)$ & $1285(751 ; 1782)$ & $1251(839 ; 2008)$ & $\begin{array}{l}P_{1-2}=0.460 \\
P_{1-3}=0.915\end{array}$ \\
\hline
\end{tabular}




\section{Continued}

\begin{tabular}{|c|c|c|c|c|c|}
\hline & IS & $90(68 ; 139)$ & $63(42 ; 94)$ & $88(65 ; 121)$ & $\begin{array}{l}P_{1-2}=0.050 \\
P_{1-3}=0.308\end{array}$ \\
\hline \multirow[t]{3}{*}{ ITRS } & OT & $117(70 ; 153)$ & $76(45 ; 130)$ & $83(57 ; 154)$ & $\begin{array}{l}P_{1-2}=0.786 \\
P_{1-3}=0.567\end{array}$ \\
\hline & TMT & $90(56 ; 136)$ & $69(50 ; 118)$ & $71(56 ; 105)$ & $\begin{array}{l}P_{1-2}=0.866 \\
P_{1-3}=0.308\end{array}$ \\
\hline & IS & $77.5(72 ; 89)$ & $76(68 ; 82)$ & $76(70 ; 86)$ & $\begin{array}{l}P_{1-2}=0.660 \\
P_{1-3}=0.566\end{array}$ \\
\hline \multirow[t]{3}{*}{$\mathrm{RR}_{\mathrm{I}}$} & OT & $105(95 ; 112)$ & $99(89 ; 105)$ & $97(90 ; 105)$ & $\begin{array}{l}P_{1-2}=0.048 \\
P_{1-3}=0.544\end{array}$ \\
\hline & TMT & $91(83 ; 96)$ & $88(77 ; 95)$ & $86(80 ; 95)$ & $\begin{array}{l}P_{1-2}=0.031 \\
P_{1-3}=0.120\end{array}$ \\
\hline & IS & $42(36 ; 49)$ & $35(29 ; 40)$ & $39(34 ; 47)$ & $\begin{array}{l}P_{1-2}=0.033 \\
P_{1-3}=0.544\end{array}$ \\
\hline \multirow[t]{3}{*}{ AMo } & OT & $47(38 ; 59)$ & $41(35 ; 52)$ & $40(35 ; 54)$ & $\begin{array}{l}P_{1-2}=0.278 \\
P_{1-3}=0.280\end{array}$ \\
\hline & TMT & $35(26 ; 41)$ & $30(26 ; 40)$ & $31(27 ; 36)$ & $\begin{array}{l}P_{1-2}=0.840 \\
P_{1-3}=0.428\end{array}$ \\
\hline & IS & $0.31(0.22 ; 0.34)$ & $0.36(0.29 ; 0.41)$ & $0.28(0.24 ; 0.32)$ & $\begin{array}{l}P_{1-2}=0.503 \\
P_{1-3}=0.966\end{array}$ \\
\hline \multirow[t]{2}{*}{$\begin{array}{c}\text { MxDMn, } \\
\text { y.e. }\end{array}$} & OT & $0.37(0.31 ; 0.46)$ & $0.43(0.31 ; 0.61)$ & $0.37(0.31 ; 0.53)$ & $\begin{array}{c}P_{1-2}=0.650 \\
P_{1-3}=0.20\end{array}$ \\
\hline & TMT & $0.29(0.24 ; 0.36)$ & $0.33(0.26 ; 0.36)$ & $0.31(0.26 ; 0.35)$ & $\begin{array}{l}P_{1-2}=0.970 \\
P_{1-3}=0.641\end{array}$ \\
\hline
\end{tabular}

Legend: ${ }^{a} I S$, initial stage; OT, orthostatic test; TMT, "through the mind" test; $p=$, the differences are statistically significant, $p<0.05$.

initial state and functional assays, compared with that of the adolescents with moderate anxiety, the total power spectrum (TP) was higher for the adolescents with high anxiety (initial, 1.2-fold; orthostatic test, 1.4-fold; and "through the mind", 1.2-fold) and low anxiety (initial 1.4-fold; orthostatic test 1.5-fold; and "through the mind"1.3-fold). The TP decreased regardless of the level of anxiety in the orthostatic test (at a moderate $(-3.2 \%)$, high $(3 \%)$ and low $(-30.1 \%)$ level of anxiety).

The test "through the mind" was accompanied by an increase in the TP of the adolescents with moderate anxiety $(+47.1 \%)$, high anxiety $(+20.8 \%)$ and low $(+34.9 \%)$ anxiety. The physiological reaction variant, characterized by a predominance of sympathetic and parasympathetic influences, was noted during the "through the mind" testing of adolescents with moderate (59.6\%), high (58.8\%) and low (55.6\%) levels of anxiety.

Our analyses indicate significant associations between our indices of ANS function and PA in the initial stage. The PA level values were significantly and negatively associated with mixed sympathetic and parasympathetic measures (MxDMn $\mathrm{r}=-0.22 ; p=0.012$ ), as well as with humoural and metabolic mediated HRV (VLF $\mathrm{r}=-0.32, p=0.041$ ). In addition, the regression dependency 
of the personal anxiety level and HRV among female and male adolescents were calculated. The results indicated that there is a significant negative moderate degree of correlation of PA and MxDMn among males ( $r=-0.23, p=0.050)$, and PA and LF $(r=-0.22, p=0.023)$ among females.

Yates's corrected $\chi^{2}$ test showed a negative association with measures of HRV (initial state) when comparing the high level of PA vs. the moderate level of PA for vagally mediated $\mathrm{HRV}\left(\mathrm{HF} \mathrm{OR}=1.38[1.0-1.93] \chi^{2}=3.8 p=0.034\right)$ and both sympathetic and parasympathetic mediated HRV in the orthostatic test (TP $\mathrm{OR}=1.54[1.0-2.39] \chi^{2}=3.99 p=0.021$, LF + VLF OR $=1.5[1.0-2.36] \chi^{2}=$ $3.98 p=0.021)$ and in the "through the mind" test (LF + VLF OR $=1.63[1.1-$ 2.39] $\chi^{2}=5.72 p=0.001$ ). Emotional and other stress was also significantly higher for the adolescents with a low and high levels of PA vs. a moderate level of PA in both tests: in the orthostatic test ("high level" $\mathrm{RR}_{\mathrm{I}} \mathrm{OR}=1.87$ [1.21 2.99] $\chi^{2}=7.96 p=0.001$ ) and in the "through the mind" test ("high level" $\mathrm{RR}_{\mathrm{I}}$ $\mathrm{OR}=1.87[1.2-2.76] \chi^{2}=7.92 p<0.001$; "low level" $\mathrm{OR}=1.88[1.23-2.88] \chi^{2}=$ $7.48 p<0.001)$. No PA association was found with any HRV parameters in different tests.

\section{Discussion}

The adaptation of adolescents to conditions of psychological stress and different loads requires the constant operation of regulatory mechanisms. As a rule, the entrance into adulthood does not take into account the individual features of autonomic regulation or PA, which is one of the initial causes of dysregulation and psychological disorders at the puberty period (Beesdo et al., 2009, de la Torre-Luque et al., 2017). The level of personal anxiety influences heart rate variability in adolescents. The orthostatic test and "through the mind" test (calculated test) are accompanied by the mobilization of functional reserves of adolescents with a different level of anxiety and the initial levelling differences of HRV. Our and other results show that the functional load during the "through the mind" test is "heavier" for adolescents with high or low anxiety (Demin et al., 2011). Functional failure of the sympathetic part of the ANS is accompanied by a compensatory increase in the activity of the parasympathetic department of the ANS. HRV may be more than just an index of healthy heart function and may in fact serve as an easily measured output of the brain's integrative system for adaptive regulation (Thayer et al., 2012, Fagan et al., 2017).

Our analyses have several important limitations. We focused on PA, and we were unable to explore the potential influence of another factors, for example, socioeconomic status, age and gender. Moodithaya and Avadhany (2012) demonstrated that the gender-related difference in parasympathetic regulation increases after age 12 years. Koenig et al., 2017 has shown, through short-term recordings, that adolescent females display lower vagal activity and a higher mean heart rate than adolescent males under resting conditions. Results on HRV in the children group in this study are in unagreement with the report of Galeev et 
al. (2002) in which they observed similar HRV for both males and females among children. In addition, we evaluated only one factors at only one time points. We also did not account for joint effects (interactions) of PA and another characteristic. Finally, our estimates were limited by incomplete modern knowledge of the dependencies in a complex system "psychological status - central NS - autonomics NS".

\section{Conclusion}

It has been shown that individual types of regulation are different not only in the autonomic balance but also in the degree of endurance of the competition loads. Sympathetic activity is most pronounced when performing a test with a mental load. In persons with high anxiety, the overall variability of the heart rhythm and indices of vagal and sympathetic activity increase with an orthostatic test, and the very low frequency profile of the HRV grows with the mental load. In individuals with low personal anxiety, activity increases due to the very low frequency component of HRV in the orthostatic test, but it increases only at the expense of the low-frequency component of HRV in the case of a mental test.

\section{Acknowledgements}

The authors are grateful to colleagues who participated in the comprehensive survey of adolescents: pediatrician N.A. Babaskina, neurologist G.G. Bicheva, PhD, school psychologists M.P. Barsem, O.A. Kolchina.

\section{Conflicts of Interest}

The authors declare no conflicts of interest regarding the publication of this paper.

\section{References}

Beesdo, K., Knappe, S., \& Pine, D. S. (2009). Anxiety and Anxiety Disorders in Children and Adolescents: Developmental Issues and Implications for DSM-V. Psychiatric Clinics of North America, 32, 483-524. https://doi.org/10.1016/j.psc.2009.06.002

de la Torre-Luque, A., Fiol-Veny, A., Bornas, X., Balle, M., \& Llabres, J. (2017) Impaired Cardiac Profile in Adolescents with an Increasing Trajectory of Anxiety When Confronting an Acute Stressor. European Child \& Adolescent Psychiatry, 26, 1501-1510. https://doi.org/10.1007/s00787-017-1009-8

Demin, D. B., Poskotinova, L. V., \& Krivonogova, E. V. (2011). The Role of the Background Thyroid Status in the Change of the EEG of Adolescents with Biofeedback by the Parameters of the Heart Rhythm. Rossiyskiy fiziologicheskiy zhurnal im.I. M. Sechenova, 97, 1262-1269.

Dzhebrailova, T. D., \& Suleymanova, R. G. (2012). Dynamics of Heart Rate Characteristics in Students with Different Personal Anxiety during Computer Testing. Byulleten' eksperimental'noy biologii i meditsiny, 153, 577-581.

Fagan, S. E., Zhang, W., \& Gao, Y. (2017). Social Adversity and Antisocial Behavior: Mediating Effects of Autonomic Nervous System Activity. Journal of Abnormal Child Psychology, 45, 1553-1564. https://doi.org/10.1007/s10802-017-0262-0

Fagundes, C. P., Murray, D. M., Hwang, B. S., Gouin, J.-P., Thayer, J. F., Sollers III, J. J., 
Shapiro, C. L., Malarkey, W. B., \& Kiecolt-Glaser, J. K. (2011). Sympathetic and Parasympathetic Activity in Cancer-Related Fatigue: More Evidence for a Physiological Substrate in Cancer Survivors. Psychoneuroendocrinology, 36, 1137-1147. https://doi.org/10.1016/j.psyneuen.2011.02.005

Galeev, A. R., Igisheva, L. N., \& Kazin E. M. (2002). Heart Rate Variability in Healthy Six-to Sixteen-Year-Old Children. Human Physiology, 28, 54-58.

https://doi.org/10.1023/A:1016529931519

Hanin, Y. L., \& Spielberger, C. D. (1981). The Development and Validation of the Russian Form of the State-Trait-Anxiety Inventory. In C. D. Spielberger \& R. Diaz-Guerrero (eds.), Cross-Cultural Anxiety. V. 2. Hemisphere Publishing Corporation.

Jarczok, M. N., Li, J., Mauss, D., Fischer, J. E., \& Thayer, J. F. (2013). Heart Rate Variability Is Associated with Glycemic Status after Controlling for Components of the Metabolic Syndrome. International Journal of Cardiology, 167, 855-861. https://doi.org/10.1016/j.ijcard.2012.02.002

Koenig, J., Rash, J. A., Campbell, T. S., Thayer, J. F., \& Kaess, M. (2017). A Meta-Analysis on Sex Differences in Resting-State Vagal Activity in Children and Adolescents. Front in Physiology, 8, 582. https://doi.org/10.3389/fphys.2017.00582

Koenig, J., Weise, S., Rinnewitz, L., Parzer, P., Resch, F., \& Kaess, M. (2018). Longitudinal Covariance of Resting-State Cardiac Function and Borderline Personality Disorder Symptoms in Adolescent Non-Suicidal Self-Injury. The World Journal of Biological Psychiatry, 19, 152-157. https://doi.org/10.1080/15622975.2017.1342046

Loerbroks, A., Schilling, O., Haxsen, V., Jarczok, M. N., Thayer, J. F., \& Fischer, J. E. (2010). The Fruits of Ones Labor: Effort-Reward Imbalance But Not Job Strain Is Related to Heart Rate Variability across the Day in 35 - 44-Year-Old Workers. Journal of Psychosomatic Research, 69, 151-159. https://doi.org/10.1016/j.jpsychores.2010.03.004

Moodithaya, S., \& Avadhany, S. T. (2012). Gender Differences in Age-Related Changes in Cardiac Autonomic Nervous Function. Journal of Aging Research, 2012, Article ID 679345. https://doi.org/10.1155/2012/679345

Shlyk, N. I. (2016). Management of Athletic Training Taking into Account Individual Heart Rate Variability Characteristics. Human Physiology, 42, 655-664. https://doi.org/10.1134/S0362119716060189

Task Force of the European Society of Cardiology and the North American Society of Pacing and Electrophysiology. (1996). Heart Rate Variability. Standards of Measurement, Physiological Interpretation and Clinical Use. European Heart Journal, 7, 354-381.

Thayer, J. F., Ahs, F., Fredrikson, M., Sollers, J. J., \& Wager, T. D. (2012). A Meta-Analysis of Heart Rate Variability and Neuroimaging Studies: Implications for Heart Rate Variability as a Marker of Stress and Health. Neuroscience \& Biobehavioral Reviews, 36, 747-756. https://doi.org/10.1016/j.neubiorev.2011.11.009

Thayer, J. F., Yamamoto, S. S., \& Brosschot, J. F. (2010). The Relationship of Autonomic Imbalance, Heart Rate Variability and Cardiovascular Disease Risk Factors. International Journal of Cardiology, 141, 122-131. https://doi.org/10.1016/j.ijcard.2009.09.543

Voltas, N., Hernández-Martínez, C., Arija, V., \& Canals, J. (2016). The Three-Year Developmental Trajectory of Anxiety Symptoms in Non-Clinical Early Adolescents. Psicothema, 28, 284-290. https://doi.org/10.7334/psicothema2015.332 